\title{
PEDAGOGICAL POTENTIAL OF THE ARTS COMPLEX IN THE PROCESS OF THE FORMATION OF AESTHETIC PERCEPTION OF JUNIOR PUPILS
}

\author{
Liudmyla Brovchak \\ Vinnytsia Mykhailo Kotsiubynskyi State Pedagogical University, Ukraine \\ Lesia Starovoit \\ Vinnytsia Mykhailo Kotsiubynskyi State Pedagogical University, Ukraine \\ Larysa Likhitska \\ Vinnytsia Mykhailo Kotsiubynskyi State Pedagogical University, Ukraine \\ Nataliia Todosienko \\ Vinnytsia Mykhailo Kotsiubynskyi State Pedagogical University, Ukraine
}

\begin{abstract}
In the research are illuminated the following subjects: the topical issue of the aesthetic development of junior pupil's personality, search for new approaches to children's education and development and their implementation to the educational process of the modern school, maximal use of pupil's creative potential in the elementary school, the formation and development of the aesthetic sense of reality, the aesthetic attitude to the surrounding world, to the nature, to the arts and applying the principle of different art forms correlation.

The use of the art at the lessons of the art cycle at establishments of primary education and approaches, which have been proposed by us, analysis of findings of experimental data allows to assume that the development of aesthetic feelings, tastes, ideals, artistic skills, competences in the sphere of art, should be an undetectable condition of the educational subjects of primary school, especially of the art cycle.

We detected the growth of the level of aesthetic perception which is connected with the development of emotional and sensitive sphere and artistic potential of junior school children, that is determined by results of applying of the proposed approach to activation of aesthetic perception of junior school-age children through the art at the lessons of the art cycle. It also determines positive changes in the tendency of humanization and the aestheticization of the educational process.
\end{abstract}

Keywords: Aesthetic sense, arts complex, artistic creativity, artistic activity, creative potential.

\section{Introduction}

The problem of the research is to find solutions to nowadays pedagogical problems of the aesthetic upbringing of the younger pupils, new approaches to the education and upbringing of children and their introduction into the educational process of modern school, maximizing the creative potential of students in 
Brovchak et al., 2020. Pedagogical Potential of the Arts Complex in the Process of the Formation of Aesthetic Perception of Junior Pupils

elementary school, formation and development of aesthetics students one of the basic components of aesthetic education; aesthetic attitude to the environment, nature, art; application of the principle of correlation of different types of art and innovative artistic and integrative technologies.

The formation of the aesthetic perception of children in elementary school is of primary importance, it provides the basis for the spiritual, intellectual and physical development of the individual. At the stage of teaching a child in an elementary school is bein formed an interest in art, artistic and creative activity. In junior school-age, children form a holistic outlook, the development of aesthetic tastes and ideals, personal attitude to the cultural achievements of society.

The pedagogical potential of art is the subject of study of many pedagogical scientists. The results of the analysis of the relevant literary sources, acquaintance with the practice of the work of primary schools show that the issue of the aesthetic development of junior pupils according to modern concepts has not yet been adequately solved, and technology, mastery of the subjects of the artistic cycle do not meet the growing demands of the present. (Zhao \& Ko, 2018).

Each type of aesthetic activity is accompanied by aesthetic perception, which has different interpretations in the scientific literature. This is the ability of the child to distinguish in the phenomena of reality and the art of processes, properties, qualities that give rise to aesthetic experiences. Aesthetic perception is a way of a special creative and cognitive activity, the skills of which are formed in the process of pedagogical influence (Holinska, 2002).

Contemporary art has a great accumulated theoretical and practical experience in improving the processes of teaching and education, based on scientific knowledge of pedagogy, psychology and music studies. The mastery of art involves three inextricable moments: technical, artistic, and analytical.

It is important to note that the educational process of using the art complex to form the aesthetic perception of junior pupils has an innovative value, it also stimulates the development of cognitive and creative abilities of pupils, the ability for creative expression, the need for artistic and creative self-realization. In the process of perceiving works of art, its essence is not limited to obtaining information but includes a spiritual and practical character. The psychological interaction of the perception of works of art and its character, aimed at enriching the spiritual world of the child and determined by two factors: first, the quality of works of art; and secondly, the child's ability to fully perceive these works. Of course, if the work of art is perceived by the child only as a sign of interest, then, as in the process of perception it will only cause boredom, its impact on the pupil will be zero. Therefore, talking about the development of aesthetic perception, it is meant that a junior pupil will get acquainted with works of art through internal 
need. This acquaintance with art will make the child spiritually richer (Starovoit, 2016).

A significant number of national and foreign scientists and educators' studies are devoted to the results of the development of ways of forming an aesthetic perception of junior pupils. At the same time, the results of the study of the relevant literary sources, as well as the generalization of the practice of the comprehensive education establishments show that this problem is not yet sufficiently solved in the light of modern educational concepts. The content of disciplines in the educational arts industry, in our opinion, has no clear methodological basis. The subject of the aesthetic cycle is often underestimated. As a consequence - every year the aesthetic literacy of pupils deteriorates; there is an inhibition of the ability to create bright representations, imaginations, and skills to operate them freely. The ability of aesthetic perception of the environment, a sense of beauty reduces, aggressiveness increases, there is a decline in spirituality. Therefore, there is a need to discover the pedagogical potential of the arts complex in the process of forming an aesthetic perception of junior pupils.

The purpose of the study is to isolate and theoretically substantiate the pedagogical conditions for the formation of aesthetic perception of younger students using the arts complex: strengthening the creative motivational basis of the process of aesthetic perception of children, taking into account psychophysiological, age and individual characteristics; creation of aesthetic environment; implementation of a systematic integrated approach to the organization of children's artistic and evaluation activities; enriching the creative potential of young pupils in the process of engaging them in artistic activities; reliance on the aesthetic experience of children; co-creation of teachers and students.

Accordingly, the following tasks have been defined: the development of aesthetic perception of reality and works of art in the junior school-age children, the expansion of both artistic and aesthetic experience and the analysis of the formation of aesthetic values, tastes, interests of the junior school-age children, the formation of aesthetic assessment of junior pupils, and interest in artistic and creative activity during the lessons of the artistic cycle.

\section{Research methods}

The experimental research was conducted during the 2018-2019. In the experimental research took part 345 junior pupils and 61 teachers, who study and work at schools of Vinnytsia city and Vinnytsia region, Ukraine.

The planning and design of the study were as follows: a defined criterionlevel approach to the diagnosis of aesthetic perception in elementary students, 
Brovchak et al., 2020. Pedagogical Potential of the Arts Complex in the Process of the Formation of Aesthetic Perception of Junior Pupils

identified components, substantiated criteria, indicators, and levels of aesthetic perception in younger schoolchildren and analyzed the state of researched quality. The pedagogical conditions and the method of their realization concerning the formation of aesthetic perception in the younger schoolchildren using the arts complex were determined, which was realized in three stages: preparatorymotivational; artistic-evaluation; creative activity.

To obtain objective results of the experimental research was selected, developed and tested a set of methods and techniques for the formation and activation of aesthetic perception of children of junior school age, as well as an empirical determination of the formation of aesthetic values, the formation of artistic and aesthetic evaluation, the development of creative activity of pupils. Namely: empirical -questionnaires, surveys, observations, testing, analysis of the results of children's creative activity, pedagogical experiment to determine the state of development of aesthetic perception of junior schoolchildren, conduct a control experiment; statistical - mathematical processing of the results of research, reflection and generalization of the results of measurements and verification of their reliability.

\section{Research results and their discussion}

Analysis of the achievements of psychological and pedagogical science to the problem that are being investigated, namely the formation of aesthetic perception of junior pupils at the lessons of the artistic cycle, allowed to determine the system of criteria for diagnostics: appraisal, activity and creativity and indicators of the level of formation of aesthetic perception of children of junior school age. It is based on the main tasks of aesthetic development: the development of artistic perception, the mastery of the amount of certain aesthetic knowledge, the formation of skills and abilities, the development of creative abilities of children (Likhitska, 2017). In the course of the research is determined the feasibility of a three-level assessment of the aesthetic perception of junior pupils, which includes conventionally named by us: elementary-fragmentary (low), emotional-formal (average), elementary-aesthetic (high) levels.

While questionnaires and tests were conducted for children, was found the true state of the formation of aesthetic perception of works of art (music, painting, poetry, and literature). The results of the study indicate that $61 \%$ of children receive musical aesthetic impressions through the media. Among children's preference prevail impressions, that either in content or form, can not be regarded as facts of art. A small part of the respondents (24\%) prefer folklore (song creativity, painting, etc.). A very small percentage of the respondents (14\%) preferred classical works of art, the choice was made by children who study in music, art schools, and studios. As regard to the artistic preferences of junior 
schoolchildren, $29 \%$ of respondents preferred children`s compositions and pop songs, folk writing and artistic creativity $-19 \%$ of respondents, fairytales $-8 \%$, classical works $-6 \%$, operas $-4 \%$, authors` compositions $-1 \%$, spiritual works $1 \%$, other kinds $-3 \%$.

In determining the level of development of aesthetic perception of works of art the following criteria were relied on: the presence of a systematic representation of different types of art and their characteristic expressions; understanding the child of the nature of images, the logic of their development, the vitality of the content; emotional attitude towards art, active emotional and aesthetic feedback on the work; the need to preserve has been formed, to continue and to increase the traditions of artistic creativity; the desire to replenish their own aesthetic experience through the perception of works of art; presence of psychophysiological comfort of the child in the process of communicating with works of art; the presence of motivated aesthetic assessment of works of art and its reflection in reality.

As a result of the experimental research were identified some features that characterize each level of aesthetic perception of junior pupils: the low - the process of creating the visual image of the subject and its image proceeds without the necessary support to analyze the characteristic features; there is no specification of the individual features of the subject; the generalization process is not related to observation; schematic, stereotyped mapping prevails; lack of a holistic decorative image; personality assessment position is completely absent; failure to reproduce even the finished samples; the average - the analysis of the characteristic features of the artistic product proceeds not sufficiently active; the main individual characteristics are not always distinguished; imperfect analysis of the selected properties; generalization does not always take place in the process of observing the surrounding reality; insufficient level of abstraction leads to stereotyped image; there is no holistic decorative image, there are signs of schematism; partial attraction to imitation, reproduction; not personally evaluated position is rather pronounced; high - the process of creating an artistic image proceeds with active analysis and synthesis of characteristic features; the pupil is able to distinguish the spatial properties of the artistic work; in the process of processing a real form into aesthetic there is a novelty of associations, inherent holistic decorative image; highly enough constructive thinking; expressive emotional and personal evaluation position.

The verification of the effectiveness of certain pedagogical conditions was carried out at the formative stage of the experiment, which took place in the establishments of primary education of Vinnytsia city in two groups of children at the same time: in the experimental group (EG) - based on the method of realization of pedagogical conditions for the formation of aesthetic perception of children at the lessons of the artistic cycle, and in the control (KG) - according to 
Brovchak et al., 2020. Pedagogical Potential of the Arts Complex in the Process of the Formation of Aesthetic Perception of Junior Pupils

the traditional, established scheme, and the standard curriculum. The method of implementing pedagogical conditions for the formation of aesthetic perception of children of junior school age involves three interrelated stages: valuemotivational, activity-developing and creative.

Valuing-motivational (preparatory) stage was aimed at creating the foundation for further development of interest in aesthetic values, works of fine art, musical treasures of Ukrainian and world classical composers, contemporary works for children, children's musical folklore, folk-song creativity, artistic play activities (Brovchak, 2017).

The main tasks at this stage were: the formation of a motivational component; activation of interest in the aesthetic activity in the process of studying art; familiarizing children with the best examples of the world art treasury. The solution to these tasks was to use our methods aimed at gradually forming an interest in the artistic creative activity of children (conversations, narration, listening to music, learning songs), as well as creating a situation of success; study of advanced pedagogical experience on this subject, methods of artistic education, namely artistic and creative (practical) methods of activating aesthetic activities, etc. Aesthetic education at this stage of the study presents forms and methods that have specifics due to the peculiarities of artistic and cognitive activity: the lessons of the artistic cycle, educational events, aesthetic conversation, narrative, method of perception and evaluation of works of art, the method of drawing music, rehearsal lessons, musical game, art project, and others.

Activity-developmental (evaluation) stage was aimed at the formation of artistic and creative competence for the implementation of the process of aesthetic education of children of junior school age. The main tasks at this stage were: assimilating a certain amount of knowledge on art; mastering some of the skills of artistic activity; formation of skills of artistic and creative activity; the ability to perceive, evaluate works of art; raising the level of aesthetic experience and erudition. Consequently, in the experimental work, we substantiated the feasibility of using the following forms of aesthetic work: of the artistic cycle; artistic educational events (holidays, performances, concerts, contests, and musical tales); individual work; creative workshops.

In the process of forming aesthetic perception of children, it is expedient to use the following methods, techniques, and exercises: conversations, stories; learning songs, role-playing and their staging; vocal exercises, vocal improvisation, singing, fun; children's musical folklore, children's opera, and musical fairy tale, artistic play; game activity; artistic creativity. Also, it is preferred to play games, namely, musical and didactic games, travel games, dramatizing games, games of entertainment, moving games with songs and dances in the process of forming the aesthetic perception of junior pupils. The purpose of the artistic and creative stage (creative activity) was to provide 
conditions for the maximum realization of children's creative potential. The main tasks at this stage of the experiment were: creative use of skills and abilities acquired by children in the process of using our artistic and pedagogical technologies; activation and development of the artistic creative activity. The realization of these tasks took place in the process of musical lessons, fine arts lessons, artistic work, educational artistic events, musical mornings, holidays, children's operas, musical tales, improvisation, dramatization and dramatization of songs, concerts, song contests, master classes, and excursions (Todosiyenko, 2013).

During the activation of the aesthetic-educational process at the lessons of the artistic cycle the following methods, techniques, and forms of work: aesthetic conversation, works of reflection, artistic exercises, interactive methods, artistic games, artistic projects, holidays, children's folklore, products of children's creativity: drawings, works-descriptions, musical improvisations, drawing of music, etc. The main means of research were the use of design artistic and pedagogical technologies at the lessons of the artistic cycle: artistic presentations, creative projects, creative exercises, and tasks: "Draw music", "I and art", "Colours of music", "Artistic portrait", "Our artistic achievements", "Mic", method of drawing of music, method of game, method of "staging and roleplaying" of musical compositions, theatrical musical tales that promote the development of creative abilities and the most complete disclosure of the potential opportunities of elementary school students.

Our experimental study involved the use of a sample of school-singing games for learning with primary school-age children, which was implemented in the work with the children of the experimental group. The growth of the level of aesthetic development for children was provided by our use of repertoire of games and songs, choreographic exercises of Ukrainian classical composers, namely the collection of V. Verhovyntsia "Vesnianochka" (Spring song): songs-games "Vesna ide" (Spring is coming), "Vyidy, vyidy sonechko" (Sun, come to us), "Oj khodyt Ivanko" (Ivanko is walking around), "A vzhe vesna” (Spring is already here), "Oj letila zozulenka" (Cuckoo was flying), "Podolianochka", "Khodyt harbuz" (Pumpkin is walking around), "Oj u vyshnevomy sadochku” (In the cherry garden), "Perepilka" (Quail), "Vyshni-chereshni” (Cherries), "I shumyt i hude" (Noising and buzzing), etc.; the song-game "Oj unadyvsia zhuravel” (Crane came again) in the record of S. Drimtsov. The level of the formation of aesthetic perception (as compared to the results of the summative experiment) gave us a positive dynamic: before the experiment - know more than one musical composition $-21 \%$, after $-40 \%$, more than four works $-54 \%$, after $-60 \%$, do not know at all musical works - before the experiment - 25\%, after - no such pupils. 
Brovchak et al., 2020. Pedagogical Potential of the Arts Complex in the Process of the Formation of Aesthetic Perception of Junior Pupils

To sum up the results of the control section, it is clear that the implementation of the methodology for implementing the pedagogical conditions for activating the aesthetic perception of children of junior school-age at the lessons of the artistic cycle contributes to raising the level of aesthetic experience to the specified activity. Thus, there was an increase in the number of children with a high level of aesthetic development - from 34\% to 39\%. Instead, the number of pupils with a low level dropped significantly from $21 \%$ to $6 \%$ of pupils. $52 \%$ of schoolchildren identified the average level of this activity, $49 \%$ after the experiment. Therefore, the qualitative and quantitative results obtained in the course of the research reveal the effectiveness of the proposed methodology for forming the aesthetic perception of junior pupils at the lessons of the artistic cycle.

The dynamics of the formation of aesthetic perception of children of junior school age in the process of engagement in artistic creative activity is reflected in Fig.1.

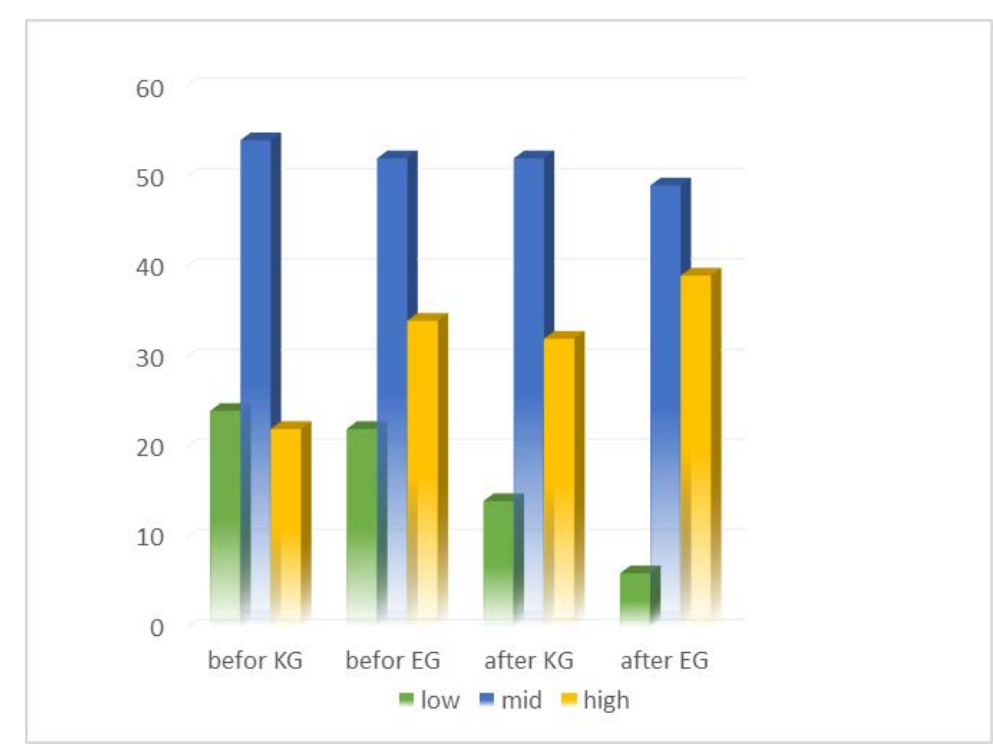

Figure 1 Dynamics of the formation of aesthetic perception of children of junior school age in the process of engagement in artistic creative activity

In the course of the experimental study, the following data were identified: significant positive changes in the structural components of the formation of aesthetic perception in younger schoolchildren using the arts complex in extracurricular educational work of EG, compared with KG.

Based on qualitative indicators of the sensual and emotional component of the formation of aesthetic perception in the arts complex of and quantitative data, a high level of EG was found by $28 \%$ and a low level by $16 \%$, which testifies to the correction of the emotional and value attitudes of the younger schoolchildren with artistic images, enrichment of the empathy of the experience of the children 
of art; the presence of increasing interest in communication with works of art; positive motivational attitudes to the process of aesthetic artistic and creative activity; getting acquainted with different ways of representing the aesthetic qualities of objects and phenomena

The analysis of the dynamic pattern in the evaluation component leads to an increase of the high level of aesthetic perception formation in younger schoolchildren as one of the most important in determining the effectiveness of the evaluation component, which was manifested in the formation of a system of skills for children to assess the emotional content of a work of art; development of the emotional-value sphere of younger schoolchildren with increased internal activity of perception of works of art; the possibility of using synesthesia, namely the method of drawing music; involving children in play arts, where the tasks in the game are presented in a hidden form, which helps to reduce the fatigue of students, increases their performance. A high-level increase of $37.7 \%$ was found, a low-level decrease was observed by $12.2 \%$.

The highest level of formation of aesthetic perception in younger schoolchildren was demonstrated by quantitative indicators of artistic and creative component as a necessary factor of creative self-improvement, which determines the level of readiness of elementary school children to participate actively in artistic and creative activity, forming the ability to actively use artistic images of the field to deepen emotional and sensory impressions and aesthetically valuable attitude to the world, reality; stimulating students' creative activity, improving their skills and ability to reproduce the author's artistic images and encouraging them to create their own. The study of the level of aesthetic perception formation in younger schoolchildren in the process of forming aesthetic perception in younger schoolchildren through the integrated use of art showed an increase of medium and high levels from $26.5 \%$ to $30.6 \%$ in the EG and the presence of minor changes in CG - within 6\%.

The highest level of formation of aesthetic perception in younger schoolchildren was demonstrated by quantitative indicators of artistic and creative component as a necessary factor of creative self-improvement, which determines the level of readiness of elementary school children to participate actively in artistic and creative activity, forming the ability to actively use artistic images of the field to deepen emotional and sensory impressions and aesthetically valuable attitude to the world, reality; stimulating students' creative activity, improving their skills and ability to reproduce the author's artistic images and encouraging them to create their own. The study of the aesthetic perception level formation in younger schoolchildren in the process of forming the aesthetic perception in younger schoolchildren through the integrated use of art showed an increase of medium and high levels from $26.5 \%$ to $30.6 \%$ in the EG and the presence of minor changes in CG - within 6\%. 
Brovchak et al., 2020. Pedagogical Potential of the Arts Complex in the Process of the Formation of Aesthetic Perception of Junior Pupils

Thus, the introduction of the proposed method of realization of the pedagogical potential of development and activation of aesthetic perception of children of junior school age in the process of creative artistic activity will contribute to a significant improvement of interest in art objects, activation of artistic thinking, the formation of practical skills at the lesson of the artistic cycle and extracurricular aesthetic and educational work, development and realization of creative abilities of children.

After using the methods of the development stimulating of aesthetic perception of junior pupils significantly increased aesthetic and value indicators, which indicates the level of aesthetic culture of children, as well as indicators of indifference, lack of understanding of works of art, indicators of interest in lowquality types of art.

As a result of the work, according to the method proposed by us, pupils of experimental groups demonstrated positive dynamics and development of aesthetic perception, the growth of aesthetic-creative abilities. The results of the control section in groups without stimulation and activation show that aesthetic perception and interest of subjects of research in works of art grows, but is formed slowly.

The pedagogical potential of using the arts complex in shaping aesthetic perception of junior pupils intend to develop the aesthetic, musical and artistic perception of children; formation of aesthetic orientation of children: stories about art, aesthetic conversations, discussion of artistic creativity, writing descriptive works; stimulating the motivation of learning activities, namely creating a situation for success; the priority of artistic and creative activity - drawing of music, artistic game, purposeful stimulation and activation of artistic and creative activity of children.

Consequently, these are the theoretical perspectives of using the arts complex in the process of forming the aesthetic perception of younger students: the innovativeness of its value, stimulation, and development of cognitive and creative abilities of students, the ability to creative expression, the need for artistic and creative self-realization. While perceiving works of art, its essence is not limited only by receiving information but contains a spiritual and practical character. Psychological interaction of perception of works of art and its character is aimed at enriching the spiritual world of the child. Therefore, it is meant that younger schoolchildren will get acquainted with works of art due to an internal need. The acquaintance with the arts will make the child spiritually richer.

\section{Conclusions}

According to the results of the research, the process of forming aesthetic perception of junior pupils based on integration and integrated use of arts involves 
the consideration of a system of certain didactic principles: the integrity of studying arts based on the unity of genetic, morphological, functional connections, taking into account the specificity of the arts, the optimal combination, and interconnection of sensory and logical, development of creative activity of pupils through their direct inclusion in the system of artistic and aesthetic relations. Creating conditions for the gradual transition of the pupil from reproductive to the creative level of development occurs through communication and activity, artistic perception of various types of art, the acquisition of artistic and aesthetic knowledge and experience, and their creative activities. Fundamental influence on the child's ability to perceive the environment, the sensation of beauty, the formation of the spiritual sphere, and aesthetic perception of the world rely on the subjects of the artistic cycle itself, while the integrative artistic and pedagogical technologies provide an increase in the level of cognitive activity and the development of creative potential of junior pupils.

The results of the experiment indicate the effectiveness of the introduced method of formation of aesthetic perception in the younger schoolchildren using the arts complex, which was revealed by employing pedagogical sections according to the developed criteria and statistical methods. The results of the study showed that the quality of formation of aesthetic perception of the elementary school students using the arts complex increases under the following pedagogical conditions: motivational basis strengthening in the process of forming the aesthetic perception of young school-age children based on dialogic interaction between teachers and students; implementation of an integrated approach and integrated application of different types of art; enriching the aesthetic experience of younger students by engaging them in creative artistic activity.

Therefore, the result of the research work was the implementation of experimental verification of the method effectiveness of realization of pedagogical conditions for the formation of the aesthetic perception of younger students using the arts complex. The technique was developed and its performance was experimentally tested. The study analyzed the methodical peculiarities of inclusion of younger schoolchildren in artistic creative activity, forms and methods of work on the formation of aesthetic perception of younger schoolchildren using the arts complex. Based on the analysis of theoretical and methodical material, the study concludes with the determined priority of the integrative methodology of the aesthetic and educational process over artistic mono-activity.

Thus, the study does not cover all aspects of the affected problem, it gives grounds for further study of the process of aesthetic education of junior pupils at the lessons of both the humanitarian and aesthetic cycle, through all educational disciplines. 
Brovchak et al., 2020. Pedagogical Potential of the Arts Complex in the Process of the Formation of Aesthetic Perception of Junior Pupils

\section{References}

Brovchak, L.S., Starovoit, L.V., \& Likhitska, L.M. (2018). Pedagogical Conditions for Creative and Artistic Development of Children of Senior Preschool Age through Art. New Educational Review, 52(2), 206-217.

Brovchak, L.S. (2017). The issue of creative activity in musical pedagogy and psychology. Science, research, development. Pedagogy, 105-113.

Golins'ka, T. (2002). Polihudozhnij rozvitok molodshih shkoljariv zasobami integraciï mistectv. Pedagogika i psihologija formuvannja tvorchoï osobistosti: problemi i poshuki, 26, 415-419.

Havigerova, J., Smetanova, V., \& Kroustkova-Moravcova, I. (2016). Talent and creativity in preschool age children: a pilot study. Studia paedagogica, 21(4), 77-98.

Simonova, J. (2015). Parents'attitudes to the selection of a primary school. Studia paedagogica, 20(3), 69-88.

Likhitska, L.M. (2017). Readiness of future teachers of music to modern approaches to teaching of artistic innovation activity. Science, research, development. Pedagogy, 126-132.

Masol, L.M. (2006). Metodika navchannja mistectva u pochatkovij shkoli. Xarkiv: Ranok.

Starovoit, L.V. (2016). Artistic-creative development of junior schoolchildren in the process of labor training. Scientific Journal «ScienceRise». Pedagogical Education, 3/5(20), 58-63

Todosiyenko, N.L. (2013). Formation of aesthetic perception of junior pupils through the multicultural activity. Naukoweprace, praktyka, opracowania, innowacje 2013 roku, 232-236.

Zhao, Ya., \& Ko, J. (2018).Workplace learning in professional development to vocational education teachers. Studia pedagogical, 23(2), 43-58. 